\title{
Introduction to Special Issue of Journal of Cross Cultural Gerontology on Aging and the Middle East
}

\author{
Allen Glicksman • May Jawad Aydin
}

Published online: 28 January 2009

(C) The Author(s) 2009. This article is published with open access at Springerlink.com

This special issue of the Journal grew out of a session on aging in the Middle East at the annual scientific meeting of the Gerontological Society of America (GSA) in 2006. There has been a growing interest on the part of GSA members about aging outside of the United States and we wanted to contribute to this developing interest by offering a session on the topic focusing on aging persons from the Middle East. This issue contains papers based on presentations at that session along with other papers that have been added to provide a broader perspective on the topic.

Why should the Middle East be considered an important area of interest in the field of cross cultural gerontology? The Middle East is a region of the world that is in a state of flux in regard to the age distribution of its residents. A recent article on aging in Arab countries reports that “...several Arab countries already are 'aged,' and population aging in the majority of Arab countries is imminent." (Yount and Sibai 2009). Similar conclusions have been reached about other countries in the region, including Iran (Ozra 2007) and Israel (Meyers 2001).

Age structure changes in the countries of this region are accompanied by other significant transformations such as greater urbanization, changes in patterns of fertility, and changes in family structure including living arrangements and migration within the region for economic, political and other reasons. Other larger economic and social changes also contribute to the reshaping of the region at both the macro and micro levels. These broad changes affect and are affected by the various cultures of the peoples in the region. We use the world "culture" when referring to the intersection of religious and ethnic norms and values.

These broad changes in the countries of the Middle East do not affect each older citizen in the same way. Each county has its own policies regarding social and health programs,

\footnotetext{
A. Glicksman $(\bowtie) \cdot$ M. Jawad Aydin

Philadelphia Corporation for Aging, Philadelphia, PA, USA

e-mail: aglicksman@aol.com

M. Jawad Aydin

School of Public Health,

UCLA Center for Health Policy Research,

Los Angeles, CA, USA
} 
services for older persons, and a broad array of policies that affect family life. Each society has significant diversity within it based on socio-economic class, urban vs. rural residence, religious and ethnic differences, and migration status. For example, among members of the growing urban middle classes, we see changes in the way filial responsibility is understood. There are further sources of diversity that may exist in only a few societies in the region, such as the kibbutz members in Israel. Finally, there are those persons who were born in the region but are aging in countries far away from their native lands.

We are keenly aware that most people are not familiar with either the rich diversity or ongoing changes that are part of the Middle East. Rather, most people's images are shaped by the popular media which often portrays the region as mired in violence and strife. While the continuing conflicts within the region are part of the story of the modern Middle East, and do affect the lives of the people who live there, including its elderly citizens, those conflicts do not tell the whole story of the region's complexity. Thus, the second reason we decided to pursue this special issue is to inform the readership regarding the diversity of the region, as well as to understand that many of the issues that are the central concerns of social gerontology in the West are also shared concerns for the peoples of this area.

One clear source of continuity that crosses all national and regional borders is the understanding of the aging experience in the context of family. Many of the changes going on in the region affect the family as a whole, including changes in the roles played by women and the patterns of fertility. Because of the importance of the family in determining the quality of life of older persons, and because we strive to have a framework for the issue that would allow us to have some conceptual clarity bridging all the articles together, we decided to select three specific themes for the special edition on aging and the Middle East. The three themes are family, diversity, and flux. By "flux" we are referring to the continuing societal change occurring across the region.

In addition to the range of topics covered in this issue, there are also a range of methodologies employed for these studies. These methodologies range from national probability surveys to qualitative analyses of small, purposefully selected samples. One article also focuses on the use of vignette methodology as a way of pursing the study of a particular group of older refugees. The simple dichotomy of quantitative versus qualitative methods does not capture the complexities of language, defining representativeness, the challenges of translation from survey instruments used in other countries, and the underlying question of interpretation of results.

Cross-cultural differences are influenced by the changing cultural values that interact with socio-demographic issues such as changes in age structure, immigration status, socio-economic status, and the role of women in the groups under study. Although only a few of the articles in the issue make explicit comparison between groups, comparing the articles as a whole allows us to see how differences in values and norms affect the lives of older persons. The cross-cultural nature of this issue becomes evident after reflection of the differences and similarities between the experiences of aging persons in this region.

Given that we see the cross-cultural aspect of this issue emerging from the set of articles as a whole rather than each article being a uniquely cross-cultural study, we will depart from the most common way of introducing the individual contributions and instead focus on the articles in terms of the country studied. We feel that by looking at the country of origin, we can better see the themes that emerge from the issue as a whole.

We begin with the case of Egypt where both articles focus on changes in family caregiving. Both Sinnunu and her colleagues as well as Boggatz and his co-authors use 
qualitative methods to explore how the role of caregiver is changing among urban Egyptians and, in the process, redefining the obligation of filial piety. According to the authors, income and social networks have an impact on the ability to seek help as well as the type of help sought. Additionally, the changes in family life and the role of women are redefining the meaning of family caregiving and the ability of the family to care for its older members. Formal and informal support for caregiving now exists at both the community and facility levels in Egypt.

The two articles from Israel each compare various groups within Israel society using survey research methods. Litwin compares three groups of older Israelis: veteran Jewish Israelis, Arab Israelis, and recent arrivals from the Former Soviet Union. Katz compares intergenerational family relations and filial norms among three similar groups of Israelis: kibbutz members, Arabs, and new immigrants from the former Soviet Union. Litwin finds that the "veterans" report better well-being than members of the other two groups. The Arab respondents in Litwin's study are generally of a lower social-economic-status than members of the other two groups but have the strongest family bonds. Katz, on the other hand, finds the lowest level of filial responsibility among kibbutz members, probably as a result of the ideological assumptions on which the kibbutz is built. In both studies, the recent immigrants from the former Soviet Union show the effects of the disruption caused by migration. In all three of Katz's groups, there are exhibited differences that raise questions about how the next generation of elders will fare.

We move next to the case of Lebanon. The two articles by Jawad and Sibai both consider social networks in Lebanese families as part of studies with very different foci. Using the life stress paradigm, Jawad places special emphasis on the relationship between social support and depressive symptomatology. She shows that there is a complex set of interactions among the domains she studies - and so family relations must be understood in a wider post-war context. Mehio-Sibai shows that co-residence with children reflects lower socio-economic-status and that co-residence is more likely in traditional families. In doing so, she also demonstrates the complex interaction of structural and cultural domains in defining family living arrangements. The lack of a government sponsored old age pension is another factor she raises, showing how government policy is also a factor in determining individual outcomes.

Finally, Torres focuses on the methodology she used to gather information on older Iranians living in exile in Sweden. Understanding the inner lives of people-their values, norms, and worldview can be a daunting task under any circumstance, especially when investigators do not share much in the way of language, culture, or life experience with the population under study. Her article provides a detailed look at one method for gaining a better understanding of how a specific group of older persons understand the world and the values and norms they use for decision making in their daily lives.

Taken together these papers provide not only a cross-cultural look at aging among persons born in or residing in the Middle East but also place the cross-cultural perspective into wider political, social, and historical context. The variety of research methods used in these studies demonstrate that there are as many ways of understanding the lives of older persons and that there are cultural and other variations among them. The universal aspects of aging - family caregiving, frailty, and intergenerational relations - are all present as unique aspects of aging in these societies which come together to shape the experiences of these elders and their family members.

We cannot end this introduction without expressing our deep thanks to everyone who participated in this effort. Each of the authors graciously cooperated with this effort, and we 
appreciate all their hard work. The reviewers were both thoughtful and prompt, and their comments gave everyone much to think about. We want to express our special thanks to the editors of the journal, Margaret Perkinson and Robert Schrauf for agreeing to "host" this special issue. Their comments have also been very helpful in shaping the contents. Perkinson also served as the formal contact for the issue, and her support and assistance throughout the process is much appreciated.

Allen Glicksman and May Jawad Aydin, January 2009

Open Access This article is distributed under the terms of the Creative Commons Attribution Noncommercial License which permits any noncommercial use, distribution, and reproduction in any medium, provided the original author(s) and source are credited.

\section{References}

Meyers, N. (2001, November 30). The graying of Israel: coping with aging population poses challenges. Jewish News Weekly of Northern California Magazine.

Ozra, N. (2007). Country report: Islamic Republic of Iran. Regional review of the Madrid international plan of action on ageing p. 7. Macao: United Nations Economic and Social Commision for Asia and the Pacific.

Yount, K. M. \& Sibai, A. (2009). The demography of aging in Arab countries. In P. Uhlenberg, International Handbook on the Demography of Aging. In press. 